\title{
Nuestra América, de José Martí: la luz que pudo haber evitado el fracaso del Mercado Común Centroamericano.
}

\section{Nuestra America by José Martí: Light that Could Have Prevented The Failure of the Central American Common Market}

\section{Nossa América, de José Martí: luz que pode ter evitado a fracasso do Mercado Comum Centro-Americano.}

\author{
Gabriela Cerdas-Ramírez \\ Jimmy Ramírez-Acosta \\ Isabel Cristina Bolaños-Villalobos \\ Escuela de Literatura y Ciencias del Lenguaje \\ Universidad Nacional de Costa Rica \\ Recibido 29/05/2014 • Aprobado 08/10/2014 \\ DOI: http://dx.doi.org/10.15359/tdna.31-57.3
}

Lo que queda de aldea en América ha de despertar. Estos tiempos no son para acostarse con el pañuelo a la cabeza, sino con las armas de almohada, como los varones de Juan de Castellanos: las armas del juicio, que vencen a las otras. Trincheras de ideas valen más que trincheras de piedra.

José Martí , Nuestra América

\section{Resumen}

El punto medular de este ensayo es identificar, desde la perspectiva martiana, algunas de las razones que propiciaron que uno de los más grandes intentos de unión de los países centroamericanos, el Mercado Común Centroamericano (MCCA), fracasara. Nuestra aproximación se centra en el período de 1962 a 1979. No tiene, por supuesto, la pretensión de ser una evaluación completa de dicho proceso; sino plantear un conjunto de aspectos generales del proceso de integración centroamericana, señalar algunas de las principales causas de su fracaso y reflexionar, desde el pensamiento martiano, las consideraciones de una estrategia de integración.

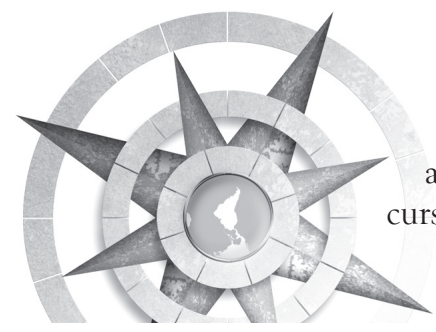

Palabras claves: José Martí, Mercado Común Centroamericano, integración centroamericana, análisis del discurso, Nuestra América 


\begin{abstract}
The main objective of this essay is to identify how one of the biggest attempts to join to identify how the Central American countries into the Central American Common Market was a failed project. Our study is focused between 1962 and 1979. It does not have the pretension of being an exhaustive or complete evaluation of such Central American endeavour; rather it aims to signal some of the general aspects of the integration process, and the possible main causes that might have lead to its unsuccessful results. Reference is made to José Martí 's ideas in Nuestra America as valid considerations that serve the analysis for an the integration strategy.
\end{abstract}

Keywords: José Martí, Central American Common Market, Central American integration, Discourse Analysis, Nuestra América

\section{Resumo}

O ponto central deste ensaio é identificar, a partir da perspectiva de Marti, algumas das razões que levaram a uma das maiores tentativas de união da América Central, o Mercado Comum Centro-Americano (MCCA) ao fracasso. A nossa abordagem centra-se no período de 1962 a 1979. É evidente que não tem a pretensão de ser uma avaliação completa do processo; mas apresenta um conjunto de aspectos gerais do processo de integração da América Central, observando algumas das principais causas de seu fracasso. Destina-se a refletir, a partir de pensamentos de Martí, considerações de uma estratégia de integração.

Palavras-chave: José Martí, Mercado Comum Centro-americano, integração da América Central, Análise do Discurso, Nossa América

Hablar de Martí es hablar de un llamado a la unión de los hombres, a la valoración del ser auténtico y al respeto de nuestros propios valores; significa hablar de ideas ligadas a la acción. Por esta razón, el discurso de Martí es tomado en este ensayo como un discurso siempre actual.

Martí fue un pensador latinoamericano que vió más allá de su época, un filósofo humanista que creyó en el hombre latinoamericano y en una identidad universal del hombre. Luchador que exhortaba a los países latinoamericanos a un reconocimiento propio, de su propia identidad, a una unión que cambiaría el proceso de desarrollo de estos países. Sus palabras lo dicen: «Es la hora del recuento, y de la marcha unida, y hemos de andar en cuadro apretado, como la plata en las raíces de los Andes» (Martí, 1939: p. 10).

Martí, con su profundo sentido de análisis, pudo visualizar los problemas de su época, los cuales, tristemente, cien años después, se mantienen vigentes. Él creyó firmemente en las relaciones interamericanas como medio para

40 Nuestra América, de José Martí: la luz que pudo haber evitado... Gabriela Cerdas-Ramírez, Jimmy Ramírez-Acosta, Isabel Cristina Bolaños-Villalobos

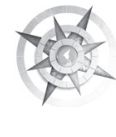


desaparecer los odios inútiles y para acrecentar la capacidad de diálogo.

Los países centroamericanos fueron, durante trescientos años, parte de una misma entidad político-administrativa, la Corona española. Sus vinculaciones económicas e infraestructurales fueron siempre muy precarias, dependientes de la metrópoli. Así, no es de extrañar que, antes de transcurrir veinte años después de lograda la independencia en 1821, el intento de la República Federal se fracturara y cada país optara por constituirse como Estado separado. Desde entonces, el restablecimiento de un Estado centroamericano pasó a ser el ideal nostálgico de los proyectos de re-vinculación regional.

Desde que el área centroamericana fue incorporada por España en el sistema mercantil-capitalista, al igual que el resto de América Latina, ha desempeñado un rol subordinado a las necesidades e intereses de los centros hegemónicos en el marco del sistema internacional capitalista.

Es un hecho comprobado que este sistema ha provocado un desarrollo desigual entre las naciones del mundo e incluso entre las regiones de una misma nación y sus ramas productivas. Esta desigualdad ha perjudicado a los países exportadores de materias primas y alimentos, al convertirlos en importadores de productos manufacturados, debido a la compleja estructura de producción y de intercambio internacional generado por el sistema de explotación capitalista. El capitalismo opera constantemente en contra de los países importadores de bienes manufacurados, lo cual se ve reflejado parcialmente en el intercambio desigual que favorece a los países productores y exportadores de bienes de consumo.

Los países de Centroamérica pertenecen al grupo de países pobres. Para superar esta situación han surgido ideas de unidad a lo largo de los años, tomando en cuenta que la pequeñez del mercado de cada uno de estos países es un obstáculo para captar las ventajas de la producción en serie o masiva. El proceso de integración económica de Centroamérica fue el primero de todos los que han tenido lugar en América Latina y el Caribe. Se perseguían, entre otros, los siguientes objetivos:

- Reducir la vulnerabilidad externa del mercado: Se reduce esa vulnerabilidad cuando las economías de los países subdesarrollados se diversifican y sustituyen importaciones, por lo cual dependen en un grado mayor de su propio abastecimiento. Con esta integración se permite diversificar las exportaciones, pues el área 
integrada constituye un mercado hacia el que pueden canalizarse importantes corrientes de productos industriales, cuya salida hacia los mercados mundiales presenta grandes dificultades.

- Aumentar la capacidad de negociación: Los países subdesarrollados que se integren tienen ante sí varias tareas que requieren una mayor capacidad de negociación; por una parte, se trata de lograr precios estables en las exportaciones de productos primarios; y por la otra, de ampliar las ventas externas de productos no tradicionales $y$, finalmente, negociar la obtención de financiamiento externo.

- Economías de escala y especialización: La integración económica regional se concibe también como un medio para facilitarles a los países subdesarrollados la organización en economías de escala y la especialización.

- La industrialización de los países en vías de desarrollo: Constituye la parte medular de la diversificación de las economías de dichos países, pues busca una menor dependencia externa y una mayor satisfacción de las necesidades de la población.

Esta dependencia la denunció muy claramente Martí en su texto, síntesis del siglo XIX, «Nuestra América»:
La incapacidad no está en el país naciente, que pide formas que se le acomoden y grandeza útil, sino en los que quieren regir los pueblos originales, de composición singular y violenta, con leyes heredadas de cuatro siglos de práctica libre en los Estados Unidos, de diecinueve siglos de monarquía en Francia (Martí, 1939: p. 12).

Los países latinoamericanos iniciaron su proceso industrial en muy distintas etapas, pero todos comenzaron por instalar industrias que no requerían grandes mercados, enormes inversiones ni tecnología compleja.

La Comisión Económica para América Latina (CEPAL) dirigió estas acciones y partió de varios supuestos racionales y necesarios, como los siguientes:

1. El estancamiento económico del Istmo está ligado a su economía predominantemente agrícola, de ahí que se considerase que la clave para el progreso estaba en iniciar un desarrollo selectivo alrededor del cual debía girar todo plan de crecimiento futuro.

2. El nivel de desarrollo de las fuerzas productivas en la actualidad es muy grande, pero también flexible, por lo que su incorporación solo puede lograrse mediante la adquisición de grandes e indivisibles unidades productivas

42 Nuestra América, de José Martí: la luz que pudo haber evitado... Gabriela Cerdas-Ramírez, Jimmy Ramírez-Acosta, Isabel Cristina Bolaños-Villalobos 
que no podría obtener y operar económicamente ningún Estado centroamericano aisladamente.

3. La experiencia histórica demuestra los daños económicos y los peligros políticos que asumen las naciones cuando permiten que la propiedad y el manejo de sus medios de producción estén en manos extranjeras.

4. Para garantizar que el plan beneficiase por igual a los cinco países del Istmo se esperaba crear empresas industriales en todos y cada uno de ellos. El desarrollo equilibrado así conseguido adquiriría las virtudes de ser fruto de un esfuerzo gradual, de costo mínimo, sostenido, de largo alcance, recíproco e irreversible, que elevaría continuamente el nivel de vida y bienestar de sus habitantes, asegurando una justa redistribución de las ganancias de la integración. Para garantizar aún más este desarrollo equilibrado operaría un fondo para el desarrollo industrial -alimentado mediante contribuciones de los cinco países y créditos externos-, el cual otorgaría asistencia financiera a las industrias de integración por establecerse, conforme a un plan de prioridades, y habría más créditos para aliviar los desajustes causados por su creación.

5. El plan de inversión industrial debía basarse en algún tipo de planificación regional en la que solo ciertos productos obtendrían las ventajas del comercio libre en la región.

Estos son los postulados con los que el MCC inició su desarrollo. Eran ideas que el propio Martí, con su discurso visionario y vigente, plasmaría de la siguiente manera:
Resolver el problema después de conocer sus elementos, es más fácil que resolver el problema sin conocerlos. Viene el hombre natural, indignado y fuerte, y de- rriba la justicia acumulada de los libros, porque no se la administra en acuerdo con las necesidades pa- tentes del país. Conocer es resol- ver. Conocer el país, y gobernarlo conforme al conocimiento, es el único modo de librarlo de tiranías (Martí, 1938:14).

La CEPAL, para echar a andar el plan de integración, consultó y coordinó su actividad con los dirigentes del sector público y privado de cada país, y en 1958 los cinco países firmaron el Tratado Multilateral (TM) y el Régimen de Industrias de Integración (RII). Ambos tuvieron una duración de diez años: 
El Tratado establecía el libre comercio o el tratamiento preferencial para los productos centroamericanos incluidos dentro de una pequeña lista adjunta, la cual sería ampliada mediante negociaciones, a fin de que al cabo de los diez años la totalidad de los productos gozara de libre comercio.

El RII preveía la creación con capitales nacionales, de industrias de integración cuyos productos serían protegidos de la competencia mediante una tarifa externa común. O sea que gozaría de un derecho monopólico en toda el área, a fin de asegurarles un mercado suficiente para que pudieran operar siquiera a su capacidad mínima (Guerra, 1982: p. 30).

No podía esperarse que estos convenios desembocaran de inmediato en un activo intercambio intrazonal de mercancías. EL TM, tímidamente, favorecía el libre comercio de una pequeña lista de productos originarios de Centroamérica. Confabulaba en contra de un activo intercambio regional inmediato, el carácter competitivo de la producción agrícola, el poco desarrollo de la actividad manufacturera artesanal y, sobre todo, la falta de carreteras y medios de transporte y de comunicación.

En aquella época la burguesía centroamericana no constituía una burguesía industrial organizada; lo que prevalecía era la pequeña fábrica o el taller artesanal. En Guatemala, que era el país más desarrollado, solo había cinco fábricas importantes. No existía, en toda el área, un fuerte empuje que se interesara en unir capitales para formar empresas de integración como las concebía la CEPAL.

EL RII exigía, además, un altísimo grado de cooperación entre Gobiernos, siendo indispensable que se hiciesen concesiones mutuas, dándose un ambiente desfavorable para echar a andar el RII.

Durante la década de 1950 Estados Unidos observó el movimiento de la integración centroamericana sin intervenir. Pero la firma de los tratados inspirados por CEPAL en 1958, TM y RII, puso en evidencia que los centroamericanos avanzaban en sus planes de integración y esto interesó a los Estados Unidos.

Los funcionarios estadounidenses se percataron de que si el movimiento integracionista continuaba en la misma dirección traería consecuencias negativas para ellos; pero si Estados Unidos lo reorientaba, la integración podía ser consistente con los objetivos e intereses norteamericanos, entre los que cabe citar los siguientes:

- Estados Unidos estaba interesado en abrir las puertas de Centroamérica a nuevos mercados

44 Nuestra América, de José Martí: la luz que pudo haber evitado... Gabriela Cerdas-Ramírez, Jimmy Ramírez-Acosta, Isabel Cristina Bolaños-Villalobos 
e inversiones de corporaciones norteamericanas. Un área de libre comercio que no presentara restricciones sobre las inversiones y ofreciera incentivos apropiados.

- Estabilización de la situación centroamericana y la defensa contra la «amenaza del comunismo». A lo largo de los años sesentas, como los planes de integración centroamericana estuvieron vinculados a la unificación de las instituciones de defensa de los cinco países, Estados Unidos estaba interesado en evitar cualquier «amenaza» a la seguridad de América Central, debido a la ubicación estratégica de la región y como entrada al Canal de Panamá.

- Combatir la influencia de la CEPAL en Centroamérica, ya que sus intereses no eran compatibles con los del Istmo, y Estados Unidos la consideraba como un rival.

Esta intromisión de los Estados Unidos la previó José Martí, muchos años antes, además la visualizó de una extraordinaria manera:

$\mathrm{Ni}$ el libro europeo, ni el libro yankee, daban la clave del enigma hispanoamericano. Los jóvenes de América se ponen la camisa al codo, hunden las manos en la masa, y la levantan con la levadura de su sudor. Entienden que se imita demasiado, y que la salvación está en crear. (1938: p. 18)

Él comprendió que el desarrollo económico de los países de América Latina, y en este caso específico de América Central, debería darse siguiendo las pautas de un autoconocimiento. Por temor a lo que certeramente llamó el Tigre de afuera, en alusión a Estados Unidos, Martí resumió toda esta problemática en esta frase: «El problema de la independencia no era el cambio de formas, sino el cambio de espíritu». (p. 16)

Sin embargo, esta independencia no se dio, y las esperanzadoras expectativas de Centroamérica de formar un Mercado Común se vieron frustradas. Para Estados Unidos la teoría defendida por la CEPAL, en cuanto a que las decisiones de inversión debían basarse en la planificación, era demasiado estatista, tendía al socialismo y, por lo tanto, era peligrosa.

Por consiguiente, a fines de la década de los cincuentas, Estados Unidos reconoció que debía tomar parte activa en los procesos de integración centroamericana para prevenir que siguiera «cursos indeseables». Así, mediante un simple ofrecimiento 
de \$ 100000000 (cien millones de dólares), negoció con los países de Honduras, El Salvador y Guatemala para que se adhirieran a las nuevas reglas del juego, firmando:

a) En febrero de 1960, el Acuerdo Tripartito de Asociación Económica. Este Tratado, suscrito a espaldas de la CEPAL, establecía el libre intercambio comercial para casi todos los productos de origen centroamericano, excluyendo el concepto de industrias de integración, so pretexto de que la creación de ellas, exigía crear impuestos para los productos similares producidos por empresas «no integradas», violando así el espíritu tripartito, que buscaba establecer el libre comercio. (Bodenheimer, 1975: p. 35)

b) En junio de 1960, protocolos adicionales para crear un fondo para el desarrollo industrial, idea que sería manipulada para dar paso después al Banco Centroamericano de Integración Económica (BCIE) (Bodenheimer, 1975: 47).

Esta intervención constituyó una de las principales causas del fracaso del Mercado Común Centroamericano, porque no se logró el desarrollo de un sistema económico equilibrado e integrado, ni la negociación de una política común sobre la inversión extranjera directa, dando lugar a que las firmas extranjeras, principalmente las norteamericanas, fueran objeto de una celosa competencia entre los distintos Gobiernos centroamericanos que rivalizaron para atraer inversión directa a su territorio.

En muchos casos, la inversión extranjera desplazó inversiones nacionales en áreas ya establecidas, en las cuales se contaba con una experiencia empresarial importante. Por lo tanto, la intervención norteamericana significó una pérdida de poder y de decisión regional en sectores estratégicos para el desarrollo.

Dentro de la línea de pensamiento de la CEPAL, el desarrollo equilibrado sería sinónimo de un proceso de crecimiento del que se beneficiarían todos los países miembros, independientemente de su posición comparativa en cuanto a niveles y tasas globales, o a saldos de sus respectivas y recíprocas balanzas comerciales.

Por lo tanto, la integración, entendida en su sentido más amplio como una profunda transformación cualitativa de las bases técnicas de la sociedad, comprende todos los sectores de actividades, y debe promoverse con el fin de abarcar a todos los países de la región, de manera que ayude a modernizar sus estructuras y a impulsar al máximo

46 Nuestra América, de José Martí: la luz que pudo haber evitado... Gabriela Cerdas-Ramírez, Jimmy Ramírez-Acosta, Isabel Cristina Bolaños-Villalobos 
su progreso técnico, un proceso de desarrollo equilibrado que no se logró con el proyecto de la integración centroamericana. Desde el comienzo hubo inconformidad entre los países de la región y sospechas en cuanto a los beneficios de la integración.

Este desarrollo desigual estuvo basado, en parte, en la revocación del RII. La libertad de invertir en cualquier país, con vistas a producir diversas mercancías exportables a los otros países del Istmo, dio como resultado final que el capital foráneo se ubicara en los países que ofrecían mayores ventajas comparativas, tales como una infraestructura económica y social, servicios y talleres de reparación, un mercado interno mínimo, obreros y personal calificado suficiente y un grado de desempleo que garantizase un salario bajo por pagar.

Los países que mejor cumplían estas condiciones eran Guatemala y El Salvador, y después Costa Rica. Nicaragua y Honduras eran países agrarios, desprovistos de condiciones adecuadas para iniciar un desarrollo industrial. De ahí que después de la firma del Tratado General, en diciembre de 1960, el capital inversionista hubiese tendido a ubicarse especialmente en Guatemala y El Salvador. Aunque las exportaciones de cada país empezaron a crecer en términos absolutos, fueron Guatemala y El Salvador los que obtuvieron las mayores ventajas económicas y los que recibieron los mejores beneficios de la integración.

Mientras ambos países empezaron a producir y exportar grandes cantidades de productos manufacturados y químicos, Honduras siguió produciendo y exportando preferentemente productos agrícolas.

El Salvador se mantuvo como importador neto de alimentos, al mismo tiempo que incrementaba su producción manufacturera exportable. Esto significaba un desarrollo desigual: mayor para Guatemala y El Salvador, menor para Honduras y Nicaragua:

La aprobación de algunos beneficios de poca envergadura otorgados a favor de Honduras, no variaron la situación. Costa Rica, que sufría un agudo déficit de divisas desde años atrás, impuso en enero de 1967 un control de divisas, afectando las exportaciones del área, hasta que un ultimátum de los otros gobiernos la obligó a que esas medidas no afectaran al área (Bodenheimer, 1975: 106).

Mientras que estos desequilibrios derivados de un desarrollo desigual ocurrían dentro de un marco de deterioro creciente de la balanza de pagos de todo el Istmo frente al resto del mundo y de un empobrecimiento 
general, especialmente de su clase trabajadora, era cada vez más claro que no sería posible resolver la situación de un país sin perjudicar a otro. Es decir, los procesos de integración entre los países que supuestamente serían sus beneficiarios se transformaron cada vez más en motivo de discordia.

El suceso más importante relacionado con estas discordias fue el conflicto armado entre Honduras y El Salvador a consecuencia de desequilibrios que el desarrollo capitalista venía generando en el área. En el fondo del problema estaba la aguda concentración de la propiedad agrícola en pocas manos en El Salvador, a costa de miles de personas que, carentes de tierras, emigraban a países vecinos para no morirse de hambre.

Esto provocó la salida de Honduras del Mercado Común y la interrupción, a través de Honduras, del comercio de El Salvador y Guatemala con Nicaragua y Costa Rica.

Se hizo necesario darle una mayor utilización a los recursos regionales. Estos recursos debían estar acorde con la realidad de los países de Centroamérica, pero esto no ocurrió y esta fue otra de las razones del fracaso del intento de unión e intercambio comercial.

Martí expuso claramente:
A lo que es, allí donde se gobierna, hay que atender para gobernar bien; y el buen gobernante en América no es el que sabe cómo se gobierna el alemán o el francés, sino el que sabe con qué elementos está hecho su país, y cómo puede ir guiándolos en junto, para llegar, por métodos e instituciones nacidas del país mismo, a aquel estado apetecible donde cada hombre se conoce y ejerce, $y$ disfrutan todos de la abundancia que la Naturaleza puso para todos en el pueblo que fecundan con su trabajo y defienden con sus vidas. (1938: p. 12)

A partir de esta acotación, se puede concluir que no era posible conseguir en Centroamérica una industrialización mejor orientada, pues se presentaba una grave insuficiencia en materia de los instrumentos requeridos para esa labor. De tal modo que, para que todos los países de la región pudieran percibir una parte significativa de los beneficios que se generarían, se necesitaba primero una base interna de producción industrial que tuviera como instrumentos principales la zona de libre comercio y el arancel común, claramente proteccionistas.

Otro elemento generador de tensiones y rupturas del ordenamiento jurídico del MCCA fue el choque de intereses de las burguesías emergentes, que ocasionó que no se diera una estructura social y política equilibrada a

48 Nuestra América, de José Martí: la luz que pudo haber evitado... Gabriela Cerdas-Ramírez, Jimmy Ramírez-Acosta, Isabel Cristina Bolaños-Villalobos 
nivel regional. Esta fue la base de muchos conflictos entre el interés regional y el interés nacional. Cada nación, en algunas ocasiones, quiso poner al MCCA a su servicio y se resistió a ceder posiciones en su mercado nacional. Volvemos a recordar al pensador latinoamericano que, como si hubiera tenido una bola de cristal en sus manos al redactar el texto «Nuestra América», divisó a los lejos estos problemas y trató de evitarlos con sus palabras:

Los pueblos que no se conocen han de darse prisa por conocerse, como quienes van a pelear juntos. Los que se enseñan los puños, como hermanos celosos, que quieren los dos la misma tierra, o el de casa chica, que le tiene envidia al de la casa mejor, han de encajar, de modo que sean una, las dos manos. (p. 9)

El evidenció lo que les podía pasar a los países de América Latina. Martí deseaba una unión entre los pueblos que serviría para progresar y desarrollarse política, económica y socialmente. Sin embargo, esta cópula debía darse sin rencores ni egoísmos, y tristemente esto no ocurrió con esta oportunidad que tenían los centroamericanos para un mejor desarrollo. Centroamérica necesitaba y necesita un diálogo interno sincero y desinteresado, el cual debería darse con todos los países del Istmo; así lo expuso Martí en su escrito: «Se ponen en pie los pueblos, y se saludan. ¿Cómo somos? se preguntan; y unos a otros se van diciendo cómo son. Cuando aparece en Cojimar un problema, no va a buscar la solución a Dantzig» (p. 18).

Esto ocasionó la tendencia de poner en la balanza los intereses nacionales frente a los intereses regionales de forma antagónica, y esto prevaleció cada vez más en el proceso de toma de decisiones:

Desde un punto de vista teórico, la integración regional debe conciliar en su seno los intereses nacionales de los países correspondientes. Esto sólo puede ser resultado y no un punto de partida, pues en un principio, y durante cierto tiempo, necesariamente se está en presencia de personalidades nacionales celosas de su identidad en su relación con el mundo exterior (Guerra, 1982:130).

Como conclusiones se pueden anotar varias: solo al cabo de los años puede esperarse que la integración permita el surgimiento de un nuevo interés en el que encuentren expresión los intereses de cada país; empero, para ello debe ser evidente para cada uno que su potencial particular requiere conjugarse con el de los demás para que se realice plenamente. 
En la experiencia de la integración centroamericana hay muchos casos de conflictos entre el interés regional y los supuestos intereses nacionales. Por regla general, se trató de intereses de empresarios particulares que, en busca de su propio beneficio, utilizaron sus relaciones con el Gobierno para impedir el libre comercio de un determinado producto o la aplicación de un determinado instrumento jurídico regional.

También se hizo presente en la experiencia centroamericana la tendencia de los grupos burgueses más fuertes a subordinar los intereses de los empresarios de otros países. Este tipo de conflicto, que demuestra la existencia profunda de intereses regionales antagónicos a los intereses nacionales, ocasionó que no se concretara una estructura políticosocial equilibrada en el proceso de integración centroamericano.

En resumen, las condiciones anteriormente descritas apuntaron claramente a que no se diera un desarrollo económico, político y social por diversas razones. La estructura social y política no fue equilibrada porque, por ejemplo, se presentaron constantes choques de intereses entre las burguesías emergentes en la región. Por otro lado, se presentó una concentración de la propiedad agrícola en pocas manos, lo que provocó el éxodo de personas de unos países a otros para poder sobrevivir.

En cuanto a la estructura política, esta sufrió un proceso de desestabilidad debido a los conflictos bélicos que se produjeron en la región. Esto provocó una desconfianza por parte de los países fuera del área y originó un ambiente de incertidumbre.

A raíz de los nuevos visos de integración que soplan en la contemporaneidad de Centroamerica con países fuera del Istmo, especialmente el Tratado de Libre Comercio de Costa Rica y México, ante los procesos de globalización e integración regional y subregional como medio hacia la unidad económica, social y política, podrían tomarse en cuenta las siguientes reflexiones:

- Se necesita retomar el concepto de ejecutar un proceso de integración gradual, recíproco y selectivo que, en forma continua y sostenida, eleve el nivel de vida material y el bienestar de todos los centroamericanos, sin discriminaciones. Este debe ser un proceso a largo plazo en el cual se tome en cuenta que los países por integrarse no pueden cambiar su estructura política, social y económica de un solo golpe, sino que se deben tomar medidas continuas para ese bienestar.

50 Nuestra América, de José Martí: la luz que pudo haber evitado... Gabriela Cerdas-Ramírez, Jimmy Ramírez-Acosta, Isabel Cristina Bolaños-Villalobos

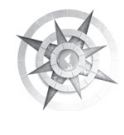


- Los planes deben serflexibles, a fin de poderlos modificar, corregir y ajustar sobre la marcha, según lo aconsejen las circunstancias imperantes.

- En el proceso de integración centroamericana -y casi ninguna teoría económica lo hace- no se consideró un aspecto de gran importancia: el área ecológica.

- Las actividades de integración, que deben promover el progreso y el desarrollo económico y social, deben abrir posibilidades reales de empleo intensivo de la fuerza de trabajo, el uso racional de los recursos naturales y de aprovechamiento útil de su condición ístmica, sin menoscabo de la seguridad de sus habitantes y de la conservación de un sano equilibrio ecológico de manera permanente.

- Las actividades de integración, que deben desarrollar económicamente el área, también deben proporcionar las bases para jugar un papel de cooperación y solidaridad con otros pueblos, como resultado de decisiones políticas independientes tomadas sin injerencia de los Gobiernos, grupos de poder y sectores que tradicionalmente han socavado la soberanía de los pueblos del Istmo.

Nuestras reflexiones coinciden con algunos puntos de la Declaración de
Cartagena, realizada en la IV Cumbre Iberoamericana en Colombia, el 14 y 15 de junio de 1994:

\section{Integración:}

- Fortalecer el sector empresarial mediante políticas de cambio tecnológico, de eficiencia y competitividad.

- Convergencia gradual y complementariedad entre los diversos esquemas subregionales de integración existentes (MERCOSUR, MERCOMUN, NAFTA, Comunidad del Caribe).

\section{Capacitación:}

- Persistir en el financiamiento sostenido para la investigación y desarrollo tecnológico para hacer efectiva la competitividad de la región en el comercio mundial.

- Promover políticas educativas y socio-laborales para adaptar fuerzas de trabajo a las transformaciones económicas.

\section{Inversión social:}

- Redefinir el papel del Estado en algunos países y racionalizar gastos en otros, con el fin de concentrar recursos para salud, justicia, educación, infraestructura social y seguridad (La Nación, junio, 1994, p. 5).

Se espera que con las estrategias de integración se llegue a un nivel de 
desarrollo más equilibrado entre los países, para que no se produzca un fracaso semejante al que se ha analizado, pues si algo útil tiene el pasado es que nos alumbra sobre lo que no debe hacerse; en tal sentido, todo lo sucedido es rico en enseñanza.

Retomamos aquí la propuesta inicial de que Martí, con su pensamiento, puede ser tomado como un hombre visionario, sin época definida, discursivamente hablando, ya que sus palabras se adaptan al problema específico de la lucha por la integración. El ideal de integración es una idea que él defendió. Sería interesante, elucubrando un poco, que las personas en la decisión política y de negociación hubiesen leído las palabras de Martí en el texto «Nuestra América», quizás las ideas y acciones hubieran caminado de una forma paralela. Esto no ocurrió así. Lo que sobrevino fue un fracaso debido a varias razones; sin embargo, con el análisis de la obra martiana y un exhaustivo esfuerzo por hacer las cosas -dejando de lado fines netamente egoístas e individualistas, y pensando en el otro como mi hermano centroamericanoel Mercomún hubiera sido una senda propicia, hubiera traído beneficios significativos en todos los ámbitos a los países del Istmo.

Centroamérica debió de haber luchado tanto con el Tigre de afuera, que fue una de las causas del fracaso de este intento de integración, como contra el Tigre de adentro que dirigió intereses egoístas en los países centroamericanos por la vía de la división y los rencores.

Si los centroamericanos, y en especial las personas que rigen los destinos de nuestros países, escucháramos las palabras de Martí y las pusiéramos en práctica cambiarían de una manera radical los rumbos, que aún hoy en día parecen oscuros e indescifrables.

Martí, pensador político y literario, artista de la palabra y hombre de ideas vive hoy. Vive con su discurso, en el que expuso, de forma brillante, soluciones a los problemas que América Latina enfrentó y que aún persisten en nuestra contemporaneidad.

\section{Referencias bibliográficas}

Bodenheimer, S.J. (1975). El Mercomún y la ayuda norteamericana en la Inversión Extranjera en Centroamérica. Costa Rica: EDUCA.

Guerra, A. (1982). Las experiencias de la integración Económica Centroamericana. Algunas reflexiones. Comercio Exterior, (12)32, 1325-1331

La Nación (13, 14, 15, 16 y 17 de junio, 1994). Cumbre Iberoamericana. Sección A.

Martí, J. (1939). Obras completas de Martí. La Habana, Cuba: Editorial Trópico.

52 Nuestra América, de José Martí: la luz que pudo haber evitado... Gabriela Cerdas-Ramírez, Jimmy Ramírez-Acosta, Isabel Cristina Bolaños-Villalobos 